BUSO, W.H.D. et al. Uso do milheto na alimentação animal. PUBVET, Londrina, V. 5, N. 22, Ed. 169, Art. 1136, 2011.

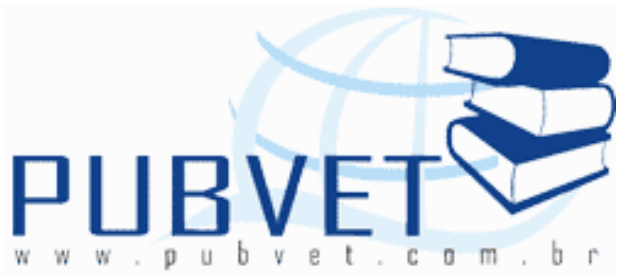

PUBVET, Publicações em Medicina Veterinária e Zootecnia.

\title{
Uso do milheto na alimentação animal
}

Wilian Henrique Diniz Buso ${ }^{1}$ Alan Soares Machado ${ }^{1}$ Luciana Borges e Silva $^{2}$ Aldi Fernandes de Souza França ${ }^{3}$

${ }^{1}$ Aluno de doutorado da Escola de Veterinária da Universidade Federal de Goiás (EV/UFG) (wilianbuso@yahoo.com) ${ }^{2}$ Professora Dra. do IFGoiano - Campus Ceres ${ }^{3}$ Professor Dr. da EV/UFG

\section{Resumo}

A pecuária brasileira ligada à exploração de diversos tipos de pastagens. $\mathrm{O}$ rebanho bovino brasileiro é dependente, de forma, crescente da necessidade de maximização da produção de forrageiras, já que, tais volumosos são a base de sua alimentação. Assim o milheto surge como uma alternativa para o período seco, devido sua grande rusticidade e adaptabilidade. É uma cultura que pode ser pastejada diretamente pelos animais suprindo toda sua necessidade alimentar, pois possui alto valor nutricional. A silagem de milheto apresenta boa composição nutricional, tornando uma boa alternativa para ser conservado afim de ser servido aos animais durante o período seco, momento em que a produção de forrageira é baixa. Os grãos podem substituir de forma parcial ou total tanto milho como o sorgo nas rações para todos os tipos de animais, pois apresentam alto valor nutritivo. 
BUSO, W.H.D. et al. Uso do milheto na alimentação animal. PUBVET, Londrina, V. 5, N. 22, Ed. 169, Art. 1136, 2011.

\section{Use of millet in the animal feeding}

\section{Abstract}

The Brazilian cattle linked to the operation of various types of grassland. The Brazilian cattle herd is dependent, in order, increasing the need for maximizing production of fodder, since such large are the basis of their food. Once the millet is an alternative for the dry season, because of its great hardiness and adaptability. It is a culture that can be directly grazed by the animals supplying all the nutritional need because it has high nutritional value. Silage millet has good nutritional composition, making it a good alternative to be preserved in order to be served to the animals during the dry season, when the forage production is low. The grains can replace partially or total as much corn as sorghum in diets for all types of animals, because they have high nutritional value.

\section{INTRODUÇÃO}

A pecuária brasileira está estreitamente ligada à exploração de pastagens naturais e cultivadas. Com a expansão do rebanho bovino brasileiro, tanto a bovinocultura de corte como a bovinocultura de leite, são dependentes, de forma, crescente da necessidade de maximização da produção de forrageiras, já que, os volumosos são a base da alimentação desses animais, o que permite produzir proteína animal de qualidade com custos menores.

A utilização de pastagens nativas é um fator limitante para a alimentação de rebanhos bovinos, devido à estacionalidade das espécies que compõem o seu ecossistema, ocorrendo perdas de peso dos animais durante o período seco do ano. A intensificação dos sistemas de produção vem exigindo terminação de animais para abate cada vez mais precoces. As gramíneas tropicais anuais podem constituir-se importantes aliadas no fornecimento de massa seca de qualidade no período mais quente do ano, pois suportam cargas 
BUSO, W.H.D. et al. Uso do milheto na alimentação animal. PUBVET, Londrina, V. 5, N. 22, Ed. 169, Art. 1136, 2011.

maiores de animais que as pastagens nativas. O consumo voluntário de forragem está intimamente relacionado à qualidade, quantidade e acessibilidade da forragem em oferta (JAMIESON \& HODGSON, 1979).

O milheto (Pennisetum americanum CL, Leeke [P. Glaucum (L) R. $\mathrm{Br}$ ]) é uma gramínea forrageira anual de verão, considerado pastagem de dias longos, muito útil para forrageamento de bovinos. É uma espécie cespitosa de porte ereto, e apresenta perfilhamento abundante. A prática tem revelado que só são bem-sucedidas as semeaduras realizadas a partir de outubro que corresponde ao inicio do período chuvoso. Sob essa condição, a forrageira germina bem e o crescimento de plantas ocorre com rapidez e compensa a semeadura antecipado, assegurando um sistema de pastejo que vise alta produtividade de forragem em menor espaço de tempo. O ciclo de produção pode estender-se de novembro a maio (FRIBOURG, 1985; CASTRO, 2002).

A região dos cerrados ocupa uma área de 207 milhões de hectares estendendo-se pela região Centro-Oeste, por parte do Sudeste, Norte e Nordeste brasileiros, constitui a última grande e contínua fronteira agrícola do planeta Terra. Desta área total dos cerrados, cerca de 40 milhões de hectares já sofreram algum tipo de ação antrópica. Mais de 50 milhões são pastagens nativas manejadas e apenas aproximadamente 5 milhões são paisagens preservadas.

No Centro Oeste há duas estações bem definidas, uma estação chuvosa e outra seca, nesta estação o rendimento das forrageiras são baixos e ainda aumenta a necessidade de forragens para os animais. O milheto surge como uma alternativa para o período seco, devido sua grande rusticidade e adaptabilidade.

\section{REVISÃO DE LITERATURA}

\section{Caracterização da espécie}

O milheto tem sido utilizado no Brasil de diversas formas, como planta forrageira para pastoreio, como produção de grãos para fabricação de 
BUSO, W.H.D. et al. Uso do milheto na alimentação animal. PUBVET, Londrina, V. 5, N. 22, Ed. 169, Art. 1136, 2011.

ração e como planta de cobertura do solo para o sistema de planto direto. O plantio direto é responsável pelo aumento da expansão da cultura no Cerrado, onde a gramínea se desenvolve bem em situações adversas de clima e solo.

O milheto pertence à família Poaceae, subfamília Panicoideae, gênero Pennisetum (BRUKEN, 1977). Há várias sinonímias botânicas usadas para esta espécie $P$. typhoides Stapf e Hubbard, $P$. americanum (L.) Leeke ou $P$. glaucum (L.) R. Br. Originário de regiões de clima tropical semi-árido.

A espécie Pennisetum glaucum possui ciclo vegetativo anual, porte ereto, podendo atingir 1 a $3 \mathrm{~m}$ de altura. As folhas medem de 0,2 a $1 \mathrm{~m}$ de comprimento e de 5 a $10 \mathrm{~mm}$ de largura. A panícula possui de 0,1 a 0,5 m de comprimento e 0,5 a $4 \mathrm{~cm}$ de diâmetro. Possui boa tolerância à seca e doenças, é tolerante a baixos níveis de fertilidade do solo, com crescimento rápido e boa produção de massa e de grãos, sendo um importante fornecedor de alimento humano (grãos) e animal (grãos e forragens) (BOGDAN, 1977).

O milheto é uma planta totalmente atóxica para os animais em qualquer estádio vegetativo, podendo ser utilizada para corte, pastejo direto, feno e silagem. Durante o período vegetativo de 120 a 150 dias, produz abundante quantidade de forragem, chegando a superar $15 \mathrm{tha}^{-1} \mathrm{e}$, manejada para silagem, pode atingir produtividades acima do milho e do sorgo (SANTOS et al. 2002).

De acordo com COIMBRA \& NAKAGAWA (2006) a época de semeadura e quantidade de cortes exercem influência no número de perfilhos emitidos pela planta, independente do estádio vegetativo em que se encontram as plantas e afetam também a produção de fitomassa e grãos de milheto. O ciclo de desenvolvimento das plantas de milheto aumentam em função do regime de cortes, quanto maior a quantidade de cortes, maior será o ciclo de milheto.

\section{Semeadura}

De acordo com KICKEL \& MIRANDA (2000) a semeadura pode ser realizada a lanço ou em linha dependendo da finalidade de uso da cultura. Para 
BUSO, W.H.D. et al. Uso do milheto na alimentação animal. PUBVET, Londrina, V. 5, N. 22, Ed. 169, Art. 1136, 2011.

pastejo o espaçamento pode variar de 0,2 a 0,3 m entre linhas com um consumo de 18 a $20 \mathrm{~kg}$ de sementes ha ${ }^{-1}$. Quando se objetiva a produção de grãos, sementes ou silagem o consumo de sementes varia de 12 a $15 \mathrm{~kg} \mathrm{ha}^{-1}$ com espaçamento de 0,4 a 0,6 m entre linhas. Gastam-se de 30 a $35 \mathrm{~kg} \mathrm{ha}^{-1}$ de semente quando a semeadura é efetuada a lanço em lavouras de soja, milho, sorgo, arroz, objetivando a formação de palhada principalmente em plantio direto, pode ser realizado manualmente, com distribuidor de calcário ou avião.

A época de semeadura pode variar de setembro a março de acordo com cada finalidade de uso do milheto. Quanto mais cedo efetua-se a semeadura mais massa e grãos serão produzidos, já nas semeaduras tardias a produção de massa será menor e poucos grãos serão produzidos pela cultura, demonstrando que a planta apresenta grande rusticidade e amplo período para sua semeadura. A planta é capaz de compensar baixas densidades de semeadura devia à sua alta capacidade de perfilhamento. A profundidade de semeadura pode variar de 2 a $4 \mathrm{~cm}$. 0 milheto tem mostrado ser a espécie de maior produção de massa no período da seca e com grande supressão de ervas daninhas $\mathrm{O}$ milheto tem mostrado ser a espécie de maior produção de massa no período da seca e com grande supressão de ervas daninhas (PEREIRA FILHO et al., 2003). 
BUSO, W.H.D. et al. Uso do milheto na alimentação animal. PUBVET, Londrina, V. 5, N. 22, Ed. 169, Art. 1136, 2011.

\section{Adubação}

A recomendação de adubação de milheto deve-se levar em conta a finalidade que a planta será explorada. Para cobertura de solo a planta funcionará como uma "bomba" recicladora de nutrientes, que dependendo da fertilidade do solo, pode-se dispensar a adubação, aproveitando o adubo residual da cultura anterior. Quando for utilizado como planta forrageira, em que há grande exportação de nutrientes removidos do solo torna-se necessário estabelecer um programa de adubação (PEREIRA FILHO et al., 2003).

De acordo com SOUSA \& LOBATO (2004) a adubação no suco de semeadura deve-se levar em consideração os resultados da análise de solo, as dosagens de $\mathrm{N}_{1} \mathrm{P}_{2} \mathrm{O}_{5}$ e $\mathrm{K}_{2} \mathrm{O}$ são: $20 \mathrm{~kg} \mathrm{ha}^{-1}, 30$ a $80 \mathrm{~kg} \mathrm{ha}^{-1}$ e 20 a $60 \mathrm{~kg} \mathrm{ha}^{-1}$, respectivamente. A adubação nitrogenada em cobertura pode variar de 40 a $60 \mathrm{~kg} \mathrm{ha}^{-1}$ de $\mathrm{N}$ e deve ser realizada em função do uso procedendo o parcelamento a partir do início do perfilhamento.

NICOLAU SOBRINHO (2007) observou que o uso de adubos verdes e orgânicos também são boas alternativas para adubação do milheto que responde a aplicação desse tipo de fertilizante, onde obteve produção de massa verde semelhante à produção utilizando adubação química.

\section{PRINCIPAIS FORMAS DE UTILIZAÇÃO}

\section{Pastejo}

Conforme resultados obtidos por MARTINS et al., (2005) o aparecimento foliar pode variar conforme a época de semeadura, precipitação pluviométrica, adubação, em que o intervalo para o aparecimento de uma folha nova variou em média de 5 a 10 dias. Quando o pastejo é realizado com as plantas em menor porte, o aparecimento foliar é mais rápido, se comparado ao pastejo de plantas de maior altura. Observou-se também que a relação folha e colmo variou conforme a planta emitiu novos perfilhos e ainda de 
BUSO, W.H.D. et al. Uso do milheto na alimentação animal. PUBVET, Londrina, V. 5, N. 22, Ed. 169, Art. 1136, 2011.

acordo com a carga de animais que foram colocados para realizar o pastejo. Quanto maior a quantidade de perfilhos maior foi a porcentagem de folha em relação ao colmo, $53,2 \%$ e $21,1 \%$ respectivamente, para uma altura de pastejo de 20 a $30 \mathrm{~cm}$. Resultados semelhantes foram encontrados por GONÇALVES \& QUADROS (2003).

Com o avanço do tempo de crescimento das plantas ocorreu decréscimo na concentração de proteína bruta (PB) nas folhas e caules, com valores alcançando no final do ciclo $8 \%$ e $2 \%$, respectivamente. Estes valores podem ser atribuídos ao estádio fenológico em que as plantas foram analisadas, ao manejo da cultura e a aplicação de adubações nitrogenadas (SCHEFFER-BASSO et al., 2004).

MONTAGNER (2004) encontrou produção de massa seca de milheto de 16.800 e $23.300 \mathrm{~kg} \mathrm{ha}^{-1}$, avaliados em alturas de $20-30$ e $40-50 \mathrm{~cm}$, respectivamente, demonstrando o alto potencial produtivo do milheto para pastejo direto. À medida que o ciclo do milheto avança há aumento da produção e acúmulo de massa seca.

À medida que o ciclo do milheto avançou ocorreu redução no percentual de oferta de lâminas foliares verdes da pastagem, bem como aumento da relação colmo-folha, contribuindo assim, para redução no consumo voluntário da forragem. Conforme a pastagem se desenvolveu, ocorreu maior oferta de massa seca e lâminas de folhas verdes. Os ovinos preferem pastar plantas mais baixas fazendo com que a pastagem tenha heterogeneidade maior em relação à altura das plantas (SCHWARTZ et al., 2003).

No trabalho de PILAU \& LOBATO (2008) novilhas prenhes com 14 e 15 meses manejadas sobre pastagem de milheto, obtiveram ganho de 0,899 kg $\mathrm{dia}^{-1}$ de peso vivo, enquanto novilhas em mesmas condições mantidas em pastagens nativas, no mesmo período, os animais ganharam $0,377 \mathrm{~kg} \mathrm{dia}^{-1}$ de peso vivo. Os teores de fibra em detergente neutro e de proteína bruta para o milheto e a pastagem nativa foram de 66 e $76 \%$ e de 14,2 e 8,4\%, respectivamente. Estas características químicas demonstram as diferenças qualitativas dos materiais e são indicadoras do maior desempenho dos animais 
BUSO, W.H.D. et al. Uso do milheto na alimentação animal. PUBVET, Londrina, V. 5, N. 22, Ed. 169, Art. 1136, 2011.

sobre pastagem de milheto.

Conforme o trabalho desenvolvido por MONTAGNER et al., (2008) manejaram a pastagem de milheto sob duas massas de lâminas foliares, $600 \mathrm{e}$ $1000 \mathrm{~kg} \mathrm{ha}^{-1}$ de massa seca e encontraram valores de massa de forragem de 1453,9 e $2498,6 \mathrm{~kg} \mathrm{ha}^{-1}$ de matéria seca. No final do ciclo de pastejo, devido ao alongamento de colmo do milheto e aumento no acúmulo de material morto, ocorreu redução na massa de lâminas foliares. À medida que o ciclo do milheto avançou e com o início do período reprodutivo, observaram também menores ofertas de lâminas foliares. Na forragem consumida, o teor de PB foi de $16,2 \%$, a FDN foi $63,7 \%$ e a digestibilidade da pastagem foi de $57,9 \%$. Os animais de corte obtiveram ganhos médios de 0,5 a $0,8 \mathrm{~kg} \mathrm{dia}^{-1}$ de pastejo.

SCARAVELLI et al., (2007) observaram que o teor de massa seca do milheto apresentou comportamento ascendente com o decorrer do pastejo. Os teores de PB decresceram com o avanço do período de utilização da pastagem e os de FDN aumentaram. Essas variações ocorreram por causa das diferenças na composição química de folhas e colmos e na variação de proporção destes componentes com o avanço do ciclo da forrageira (Tabela 1).

TABELA 1 - Teor de massa seca, teores de proteína bruta e fibra em detergente neutro de pastagens de milheto

\begin{tabular}{cccccc}
\hline \multirow{2}{*}{$\begin{array}{c}\text { Datas de } \\
\text { Avaliação }\end{array}$} & MS & \multicolumn{2}{c}{ PB (\%) } & \multicolumn{2}{c}{ FDN (\%) } \\
\cline { 3 - 6 } & $\left(\mathrm{kg} \mathrm{ha}^{-1}\right)$ & $\begin{array}{c}\text { Pré- } \\
\text { pastejo }\end{array}$ & $\begin{array}{c}\text { Pós- } \\
\text { pastejo }\end{array}$ & $\begin{array}{c}\text { Pré- } \\
\text { pastejo }\end{array}$ & Pós-pastejo \\
\hline $29 / 01$ & 4.000 & 22,93 & 22,45 & 58,97 & 65,38 \\
$11 / 02$ & 3.570 & 16,22 & 16,04 & 57,91 & 65,38 \\
$18 / 03$ & 5.140 & 15,88 & 11,80 & 55,29 & 61,21 \\
Médias & 4.240 & 18,34 & 16,77 & 57,39 & 62,82 \\
\hline
\end{tabular}

FONTE: Adaptado de SCARAVELLI et al., (2007)

Houve decréscimo linear diário na quantidade de lâminas foliares presente no pasto e ofertada aos animais, à medida que as plantas foram 
BUSO, W.H.D. et al. Uso do milheto na alimentação animal. PUBVET, Londrina, V. 5, N. 22, Ed. 169, Art. 1136, 2011.

pastejadas pelos animais como pode ser observado na Figura 1. Os animais consomem maiores quantidades de folhas em relação a outras partes da planta, em virtude da sua menor resistência à quebra pela mastigação. A quantidade de lâminas foliares no final do período de pastejo ficou abaixo da exigência diária de MS dos animais devido ao início do florescimento do milheto, quando houve redução do crescimento foliar pela maior translocação de assimilados para o desenvolvimento da inflorescência. A redução da quantidade de lâminas foliares na estrutura da pastagem foi resultado do desaparecimento deste componente nos estratos acima de $30 \mathrm{~cm}$, provavelmente pela maior acessibilidade e preferência dos animais na colheita de lâminas foliares nos horizontes superficiais (ROMAN et al., 2008).

JOCHIMS et al., (2010) trabalhando com milheto em sistema de pastejo com cordeiras, observaram que a pastagem de milheto apresentou teor de PB de 16,61, FDN de 59,29 e disgestibilidade de 54,67. Neste mesmo trabalho observaram que os animais que não receberam suplementação com milho e farinha de mandioca, permaneceram mais tempo pastejando, pois a quantidade de milheto consumido são maiores quando não recebem alimentação suplementar. Resultados próximos foram obtidos por BRUM et al., (2008) e CAMARGO et al., (2009). 
BUSO, W.H.D. et al. Uso do milheto na alimentação animal. PUBVET, Londrina, V. 5, N. 22, Ed. 169, Art. 1136, 2011.

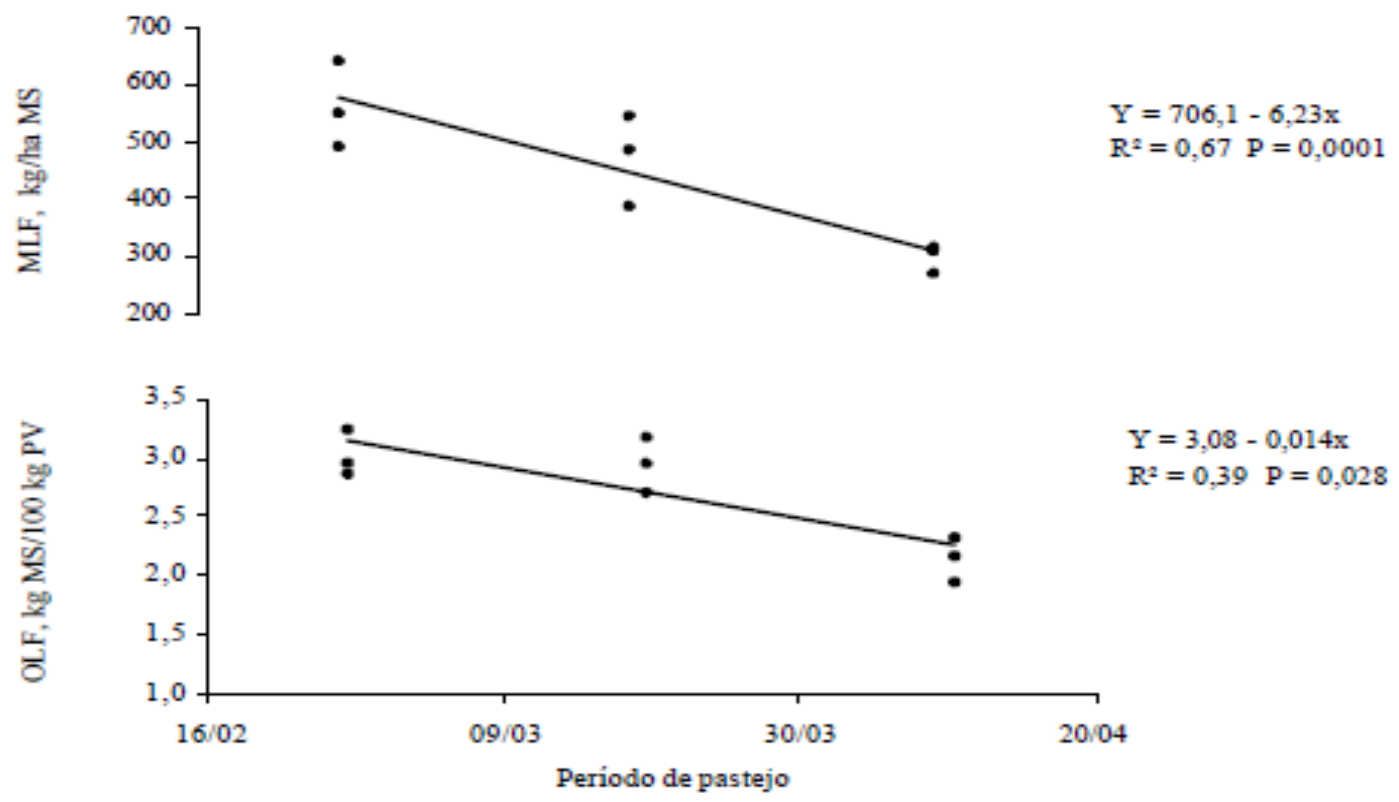

FIGURA 1 - Valores médios observados (pontos) e estimados (linha) de massa de lâminas foliares e oferta de lâminas foliares em pastagem de milheto ao longo do período de pastejo (ROMAN et al., 2008)

Segundo MOOJEN et al., (1999) o aumento na adubação nitrogenada promoveu incrementos na produção de forragem. Observaram ainda que a ocorrência de uma relação linear entre o ganho de peso diário e os níveis de nitrogênio utilizados, conforme demonstra a Figura 2. Na Figura 3 observa-se uma relação linear entre a capacidade de suporte e as doses de nitrogênio, à medida que aumentaram os níveis de nitrogênio aumentou a capacidade de suporte da pastagem. Estes fatores ocorreram devido ao aumento na produção de forragens a medida que aumentou os níveis de nitrogênio. 
BUSO, W.H.D. et al. Uso do milheto na alimentação animal. PUBVET, Londrina, V. 5, N. 22, Ed. 169, Art. 1136, 2011.

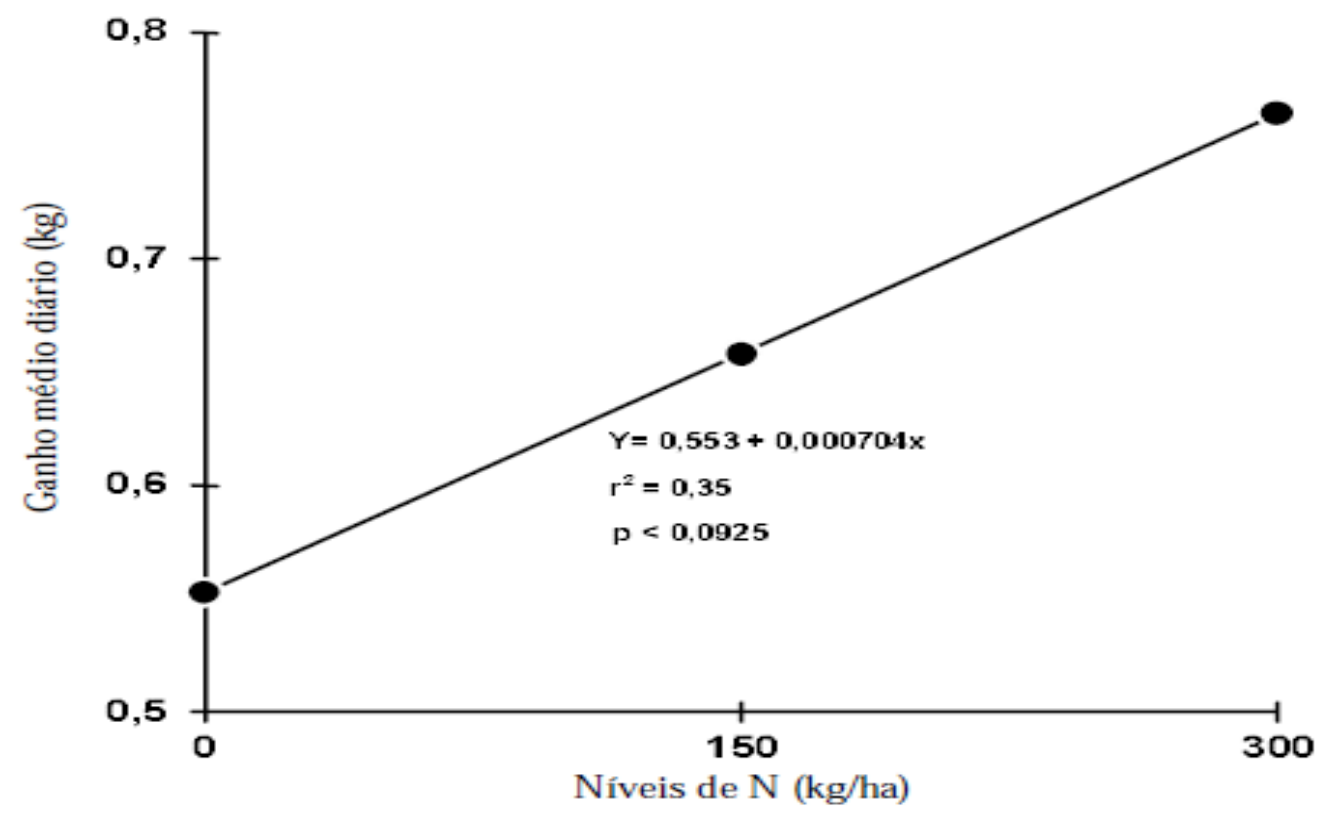

FIGURA 2 - Ganho médio diário obtido em pastagem de milheto em função dos níveis de nitrogênio aplicados (MOOJEN et al., 1999)

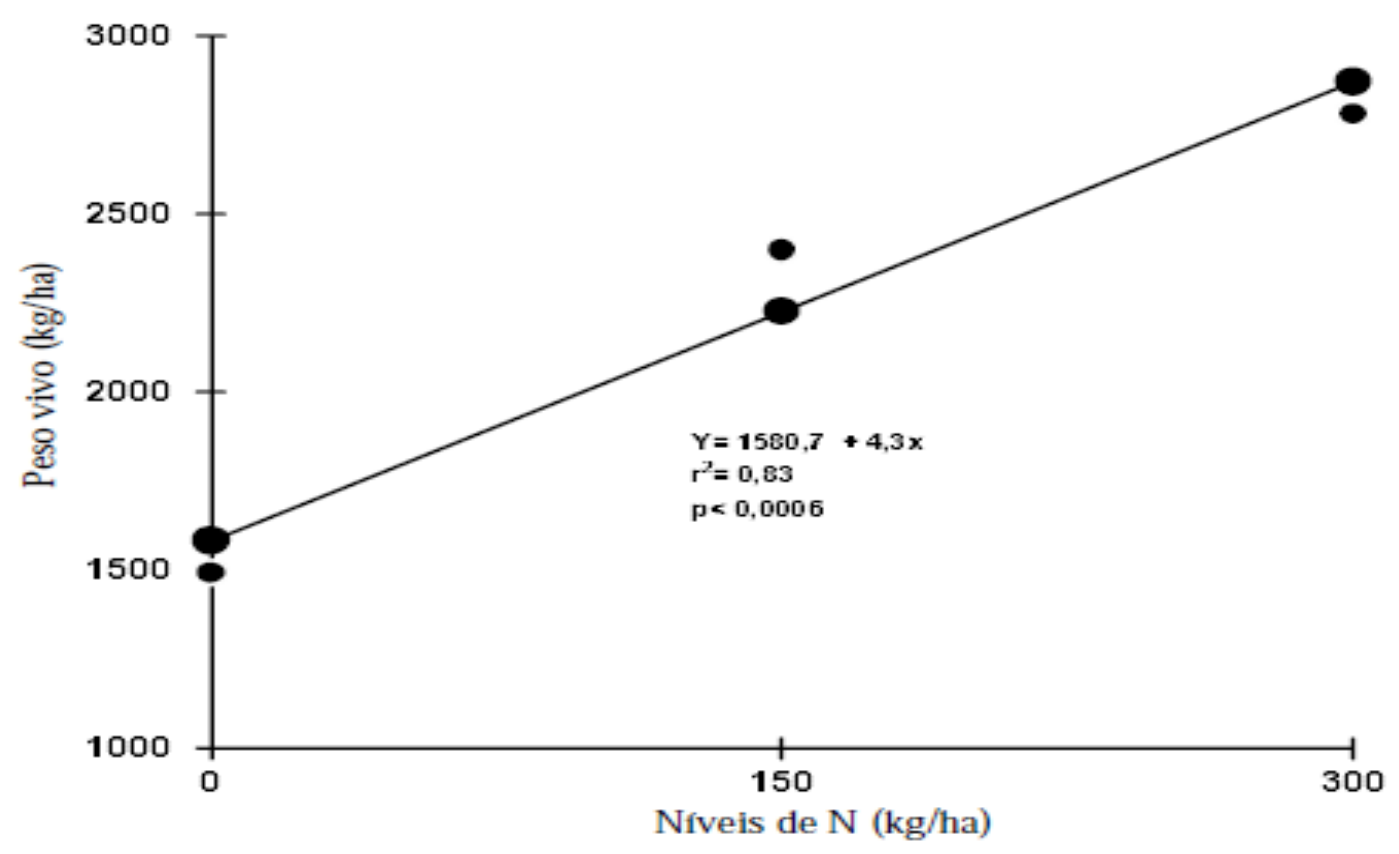

FIGURA 3 - Carga animal média expressa em peso vivo $\left(\mathrm{kg} \mathrm{ha}^{-1}\right)$ em pastagens de milheto em função dos níveis de nitrogênio aplicados (MOOJEN et al., 1999) 
BUSO, W.H.D. et al. Uso do milheto na alimentação animal. PUBVET, Londrina, V. 5, N. 22, Ed. 169, Art. 1136, 2011.

COSTA (2009) observou que a relação folha/colmo da pastagem de milheto nos estádios vegetativos e reprodutivos foi de 49 e 31\%, respectivamente. Produção de massa seca e proteína bruta foi de $16,4 \mathrm{t} \mathrm{ha}^{-1} \mathrm{e}$ $16,7 \%$, respectivamente, avaliados durante o pastejo dos animais.

Quando utilizado sob pastejo rotativo, as características estruturais do milheto são afetadas pelo período de descanso. Para o manejo adequado, é necessário período de descanso suficiente para a expansão completa de 1,5 a 2,0 novas folhas. O período de descanso exerce influência no número de folhas vivas expandidas (PEDROSO et al., 2009).

\section{Uso do milheto como silagem}

A silagem é resultante da fermentação anaeróbica de plantas forrageiras, possuindo quantidades adequadas de massa seca. É um processo muito importante para conservação de plantas forrageiras para servir de alimento, durante os períodos de escassez de forragens em todo o mundo. No Brasil, o uso da silagem é realizado em razão da produção irregular das plantas forrageiras durante a estação mais seca do ano.

A produção de massa seca de milheto cultivado em safrinha tem demonstrado produtividades satisfatórias como apresentado na Figura 4, mostrando sua alta capacidade de produção em épocas de ausência de chuvas (GUIMARÃES JÚNIOR, 2003).

AMARAL (2003) observou teores de massa seca para milheto ensilado aos 70 dias após a semeadura de $23,53 \%$ e aos 90 dias foi de $34,29 \%$. Os teores de proteína bruta foram de $10,06 \%$ e $8,47 \%$, respectivamente. A fibra em detergente neutro foram de $75,44 \%$ e $72,58 \%$, respectivamente. A fibra em detergente ácido foram de 38,06\% e 37,83\%, respectivamente (Tabela 2). Resultados semelhantes foram encontrados por GUIMARÃES JÚNIOR (2006). 
BUSO, W.H.D. et al. Uso do milheto na alimentação animal. PUBVET, Londrina, V. 5, N. 22, Ed. 169, Art. 1136, 2011.

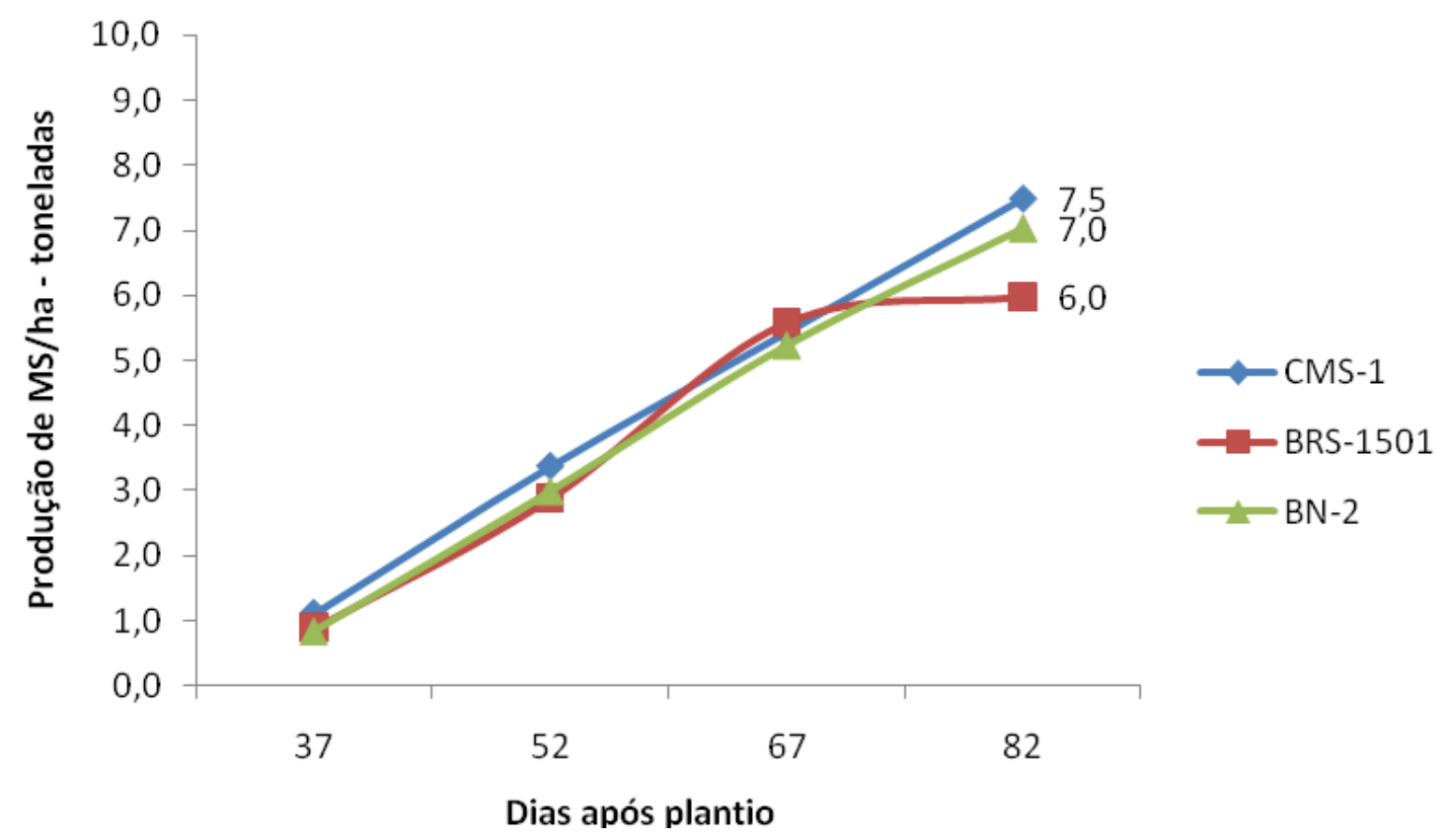

FIGURA 4 - Produção de matéria seca por hectare de três cultivares de milheto plantados em período de safrinha (GUIMARÃES JÚNIOR, 2003)

De acordo com GUIMARÃES JÚNIOR et al., (2005), não foram observadas alterações significativas nos teores de matéria seca entre os vários materiais originais e a silagem, entre os diferentes tempos de ensilagem, para a mesma cultivar e ainda comparando entre as cultivares na mesma época de ensilagem (Tabela 3). Obtiveram também valores de proteína bruta superiores aos encontrados em outras culturas utilizadas para produção de silagem, demonstrando que o valor nutricional da silagem de milheto é superior quanto ao seu conteúdo protéico, conforme Tabela 4. 
BUSO, W.H.D. et al. Uso do milheto na alimentação animal. PUBVET, Londrina, V. 5, N. 22, Ed. 169, Art. 1136, 2011.

TABELA 2 - Composição bromatológica da silagem de três cultivares de milheto submetidas a duas idades de corte

\begin{tabular}{|c|c|c|c|}
\hline \multirow{3}{*}{ Cultivares } & \multicolumn{2}{|c|}{ Idade (dias) } & \multirow{3}{*}{ Média } \\
\hline & \multicolumn{2}{|c|}{ Matéria seca (\%) } & \\
\hline & 70 & 90 & \\
\hline BRS 1501 & $22,89 \mathrm{aB}$ & $32,40 \mathrm{bA}$ & $27,64 b$ \\
\hline BN1 & $23,09 a B$ & 33,24 bA & $28,16 b$ \\
\hline Comum & $24,61 a B$ & 37,23 aA & $30,92 \mathrm{a}$ \\
\hline Média & $23,53 \mathrm{~B}$ & $34,39 \mathrm{~A}$ & \\
\hline \multicolumn{4}{|c|}{ Proteína bruta (\%MS) } \\
\hline BRS 1501 & 9,83 aA & $8,71 \mathrm{aA}$ & $9,27 \mathrm{a}$ \\
\hline BN1 & $10,22 \mathrm{aA}$ & 8,50 aA & 9,36 a \\
\hline Comum & $10,14 \mathrm{aA}$ & $8,21 \mathrm{aA}$ & 9,18 a \\
\hline Média & $10,06 \mathrm{~A}$ & $8,47 \mathrm{~B}$ & \\
\hline \multicolumn{4}{|c|}{ Fibra em detergente neutro (\%MS) } \\
\hline BRS 1501 & $78,41 \mathrm{aA}$ & $73,71 \mathrm{aA}$ & $76,01 \mathrm{a}$ \\
\hline BN1 & 75,06 aA & $73,15 \mathrm{aA}$ & $74,11 \mathrm{a}$ \\
\hline Comum & $72,84 \mathrm{aA}$ & 70,97 aA & $71,90 \mathrm{a}$ \\
\hline Média & $75,44 \mathrm{~A}$ & $72,58 \mathrm{~A}$ & \\
\hline \multicolumn{4}{|c|}{ Fibra em detergente ácido (\%MS) } \\
\hline BRS 1501 & 38,92 aA & 38,98 aA & $38,95 \mathrm{a}$ \\
\hline BN1 & 38,59 aA & $36,81 \mathrm{aA}$ & $37,70 \mathrm{a}$ \\
\hline Comum & 36,66 aA & $37,70 \mathrm{aA}$ & 37,18 a \\
\hline Média & $38,06 \mathrm{~A}$ & $37,83 \mathrm{~A}$ & \\
\hline
\end{tabular}

Médias seguidas de mesma letra minúsculas nas colunas e maiúscula na linha não diferem estatisticamente pelo teste de Tukey a $5 \%$.

FONTE: AMARAL (2003) 
BUSO, W.H.D. et al. Uso do milheto na alimentação animal. PUBVET, Londrina, V. 5, N. 22, Ed. 169, Art. 1136, 2011.

TABELA 3 - Matéria seca (\%) no material original (MO) e nas silagens de três genótipos de milheto, após diferentes períodos de fermentação

\begin{tabular}{cccccccc}
\hline & & \multicolumn{5}{c}{ Dias após a ensilagem } \\
\cline { 3 - 7 } Genótipo & MO & 1 & 5 & 7 & 14 & 28 & 56 \\
\hline CMS-1 & $23,36 \mathrm{Aa}$ & $24,49 \mathrm{Aa}$ & $23,84 \mathrm{Aa}$ & $23,66 \mathrm{Aa}$ & $23,46 \mathrm{Aa}$ & $23,89 \mathrm{Aa}$ & $23,91 \mathrm{Aa}$ \\
BRS1501 & $23,08 \mathrm{Aa}$ & $24,03 \mathrm{Aa}$ & $23,08 \mathrm{Aa}$ & $23,12 \mathrm{Aa}$ & $23,58 \mathrm{Aa}$ & $24,19 \mathrm{Aa}$ & $23,28 \mathrm{Aa}$ \\
BN-2 & $23,08 \mathrm{Aa}$ & $23,48 \mathrm{Aa}$ & $23,63 \mathrm{Aa}$ & $22,64 \mathrm{Aa}$ & $24,01 \mathrm{Aa}$ & $23,75 \mathrm{Aa}$ & $23,59 \mathrm{Aa}$ \\
\hline
\end{tabular}

TABELA 4 - Proteína bruta (\% da matéria seca) no material original (MO) e nas silagens de três genótipos de milheto, após diferentes períodos de fermentação

Dias após a ensilagem

\begin{tabular}{cccccccc}
\cline { 3 - 7 } Genótipo & MO & 1 & 5 & 7 & 14 & 28 & 56 \\
\hline CMS-1 & $10,65 \mathrm{Ab}$ & $10,23 \mathrm{Ab}$ & $10,20 \mathrm{Ab}$ & $10,49 \mathrm{Ab}$ & $9,59 \mathrm{Bb}$ & $9,96 \mathrm{Ab}$ & $10,15 \mathrm{Ab}$ \\
BRS1501 & $11,68 \mathrm{Aa}$ & $10,96 \mathrm{Aa}$ & $10,96 \mathrm{Aa}$ & $11,25 \mathrm{Aa}$ & $10,91 \mathrm{Aa}$ & $11,25 \mathrm{Aa}$ & $11,32 \mathrm{Aa}$ \\
BN-2 & $10,51 \mathrm{Ab}$ & $9,68 \mathrm{Ab}$ & $9,82 \mathrm{Ab}$ & $9,92 \mathrm{Ab}$ & $9,87 \mathrm{Ab}$ & $10,27 \mathrm{Ab}$ & $9,73 \mathrm{Ab}$ \\
\hline
\end{tabular}

Média $\quad 10,95$ A $\quad 10,29$ B $\quad 10,33$ B $\quad 10,55$ B $\quad 10,12$ B $\quad 10,49$ B $\quad 10,40$ B

Médias seguidas por letras maiúsculas iguais, na mesma linha, e minúsculas na coluna, na mesma coluna, não diferem entre si pelo teste SNK a 5\%.

FONTE: Adaptado de GUIMARÃES JÚNIOR (2005) 
BUSO, W.H.D. et al. Uso do milheto na alimentação animal. PUBVET, Londrina, V. 5, N. 22, Ed. 169, Art. 1136, 2011.

$\mathrm{Na}$ Tabela 5 são apresentados os valores nutricionais de três cultivares de milheto. Esses resultados demonstram a qualidade de sua silagem e seu alto potencial nutritivo. Apresentando altos teores de proteína bruta que melhora o desenvolvimento dos microorganismos ruminal, baixas quantidades de lignina fração que não é digerida no rúmen animal (GUIMARÃES JÚNIOR, 2006).

TABELA 5 - Teores de massa seca, proteína bruta, fibra em detergente neutro, fibra em detergente ácido, celulose, hemicelulose e lingnina da silagem em três genótipos de milheto

\begin{tabular}{cccc}
\hline & \multicolumn{3}{c}{ Genótipos } \\
\cline { 2 - 4 } Parâmetros & BRS - 1501 & NPM - 1 & CMS - 3 \\
\hline MS (\%) & 21,28 & 22,72 & 20,99 \\
PB (\%) & 11,83 & 10,73 & 11,45 \\
FDN (\%) & 70,54 & 71,22 & 71,02 \\
FDA (\%) & 37,70 & 39,71 & 39,37 \\
Celulose (\%) & 35,78 & 37,06 & 37,40 \\
Hemicelulose (\%) & 32,84 & 31,71 & 31,65 \\
Lignina (\%) & 1,92 & 2,65 & 1,97 \\
\hline
\end{tabular}

FONTE: Adaptado de GUIMARÃES JÚNIOR (2006)

A população de plantas não apresentou efeitos significativos na produção de massa verde e massa seca para silagem nem na produção de massa seca da palhada obtida da parte aérea da planta no estádio de maturação completa do grão. As produções máximas de massa verde e de 
BUSO, W.H.D. et al. Uso do milheto na alimentação animal. PUBVET, Londrina, V. 5, N. 22, Ed. 169, Art. 1136, 2011.

massa seca para silagem foram obtidas com a população de 80 mil plantas ha' 1, conforme Tabela 6 (MOREIRA et al., 2003).

TABELA 6 - Produção de biomassa para silagem e palhada, em milheto pérola (Pennisetum glaucun (L.) R. Brown) Cv. ENA 1 em diferentes populações de plantas

\begin{tabular}{|c|c|c|c|c|}
\hline $\begin{array}{l}\text { Número de } \\
\text { plantas ha-1 }\end{array}$ & $\begin{array}{c}\text { Massa verde } \\
\text { para silagem } \\
\left(\mathrm{kg} \mathrm{ha}^{-1}\right)\end{array}$ & $\begin{array}{c}\text { Massa seca } \\
\text { para silagem } \\
\left(\mathrm{kg} \mathrm{ha}^{-1}\right)\end{array}$ & $\begin{array}{l}\text { Massa verde da } \\
\text { palhada (kg ha- } \\
\left.{ }^{1}\right)\end{array}$ & $\begin{array}{l}\text { Massa seca da } \\
\text { palhada (kg ha } \\
\left.{ }^{1}\right)\end{array}$ \\
\hline 20.000 & $16250,0 \mathrm{~A}$ & $6403,3 \mathrm{~A}$ & $6868,3 \mathrm{~A}$ & $2795,0 \mathrm{~A}$ \\
\hline 40.000 & $19387,5 \mathrm{~A}$ & $6187,5 \mathrm{~A}$ & 7356,3 A & $3121,0 \mathrm{~A}$ \\
\hline 60.000 & $19558,3 \mathrm{~A}$ & $6210,0 \mathrm{~A}$ & 8127,9 A & $3387,5 \mathrm{~A}$ \\
\hline 80.000 & $20779,2 \mathrm{~A}$ & $6722,5 \mathrm{~A}$ & $6745,7 \mathrm{~A}$ & $2910,0 \mathrm{~A}$ \\
\hline
\end{tabular}

Médias seguidas de mesma letra, nas colunas, não diferem estatisticamente entre si, pelo teste de Tukey a $5 \%$ de probabilidade.

FONTE: MOREIRA et al., (2003)

\section{Uso do grão de milheto na formulação de ração}

RIBEIRO et al., (2004) observaram que não ocorreu redução no consumo de ração pelas vacas, obtendo igual aceitação entre os animais que consumiram grão de milheto e milho. Os dados bromatológicos dos grãos de milho e milheto estão na Tabela 7. Os animais obtiveram aceitação do milheto igual o milho. Observaram ainda que o milheto não afetou os teores de gordura e de proteína no leite e não provocou redução na produção de leite.

Segundo FRANÇA et al., (1996), a inclusão de milheto na formulação de rações para cabras em lactação proporcionou aumento de produção de leite quando substituiu o milho pelo milheto até o nível de $50 \%$, demonstrando que 
BUSO, W.H.D. et al. Uso do milheto na alimentação animal. PUBVET, Londrina, V. 5, N. 22, Ed. 169, Art. 1136, 2011.

o milheto é uma alternativa para substituir o milho nas rações para animais em lactação.

TABELA 7 - Análise bromatológica dos grãos de milho e milheto (\% MS)

\begin{tabular}{lcc}
\hline \multicolumn{1}{c}{ Composição bromatológica } & Milho & Milheto \\
\hline Proteína Bruta & 8,5 & 15,2 \\
Fibra em detergente ácido & 2,1 & 6,5 \\
Amido & 71,7 & 62,0 \\
\hline
\end{tabular}

FONTE: Adaptado de RIBEIRO et al., (2004)

De acordo com BASTOS et al., (2006) a utilização de até $75 \%$ de grãos de milheto em rações para suínos em crescimento e terminação é viável em termos nutricionais. Na fase de crescimento de suínos, não observaram diferenças no consumo diário de ração, no ganho de peso e na conversão alimentar. Já nos suínos em terminação à medida que houve aumento de milheto na ração ocorreu aumento no consumo. Resultados semelhantes foram obtidos por BASTOS et al., (2002).

BASTOS, et al., (2005) trabalharam com três variedades de milheto. Os resultados da análise bromatológica de milho e de milheto estão na Tabela 8. Constataram teores de PB de milheto cerca de $47 \%$ acima que a de milho, pois os grãos de milheto por serem menores possuem uma maior quantidade de gérmen que possui maiores teores de proteína.

A porcentagem de postura e o consumo diário de ração por codornas não foram observados nenhuma diferença quando substituiu milho por milheto, quando foi analisado o peso médio dos ovos a ração com adição de milheto aumentou significativamente o peso dos ovos, possivelmente pelo maior teor de proteína presente no milheto. Estes resultados demonstram que o milheto pode substituir o milho na composição de rações para alimentação de codornas 
BUSO, W.H.D. et al. Uso do milheto na alimentação animal. PUBVET, Londrina, V. 5, N. 22, Ed. 169, Art. 1136, 2011.

poedeiras (LEANDRO et al., 1999). Resultados semelhantes foram encontrados por CAFÉ et al., (1999) trabalhando com poedeiras comerciais.

TABELA 8 - Composição química e energética de milho e de três cultivares de milheto

\begin{tabular}{lcccc}
\hline Composição bromatológia & MILHO & COMUM & IAPAR & BN-2 \\
\hline Matéria seca (\%) & 87,10 & 90,46 & 86,73 & 87,31 \\
Proteína bruta (\%) & 9,84 & 15,34 & 13,62 & 14,44 \\
FDN (\%) & 13,09 & 20,58 & 12,12 & 13,98 \\
FDA (\%) & 3,84 & 4,67 & 3,81 & 3,93 \\
\hline
\end{tabular}

FONTE: Adaptado de BASTOS et al., (2005)

\section{Fitomassa}

SILVA et al., (2003) observaram que a produção de massa verde do milheto varia conforme a época de semeadura. Nas semeaduras mais tardias, normalmente ocorre redução de produção, principalmente pela falta de chuvas. A densidade de semeadura também exerce influência na produção de massa verde.

Resultados obtidos por PIRES et al., (2007) mostram que a massa seca de três cultivares de milheto aumentou, à medida que as plantas atingiam o florescimento pleno conforme demonstrado na Tabela 9. A produção de fitomassa atinge o máximo por ocasião do florescimento pleno das plantas.

CAZETTA et al., (2005) encontraram teores de massa seca para o milheto de $10.673 \mathrm{~kg} \mathrm{ha}^{-1}$ e o consórcio de milheto-crotalária $8.455 \mathrm{~kg} \mathrm{ha}^{-1}$. Isso se deve ao fato do milheto possuir um desenvolvimento inicial mais rápido que a crotalária.

Conforme TEIXEIRA et al., (2008) milheto consorciado com feijão de porco (FP) produziu $3.275 \mathrm{~kg} \mathrm{ha}^{-1}$ de massa seca, milheto solteiro (M) e consorciado com guandu-anão (GA) produziram 2.907 e $2.505 \mathrm{~kg} \mathrm{ha}^{-1}$ de massa seca, respectivamente. Em ambos consórcios o milheto contribui com 
BUSO, W.H.D. et al. Uso do milheto na alimentação animal. PUBVET, Londrina, V. 5, N. 22, Ed. 169, Art. 1136, 2011.

$51,4 \%$ (M+FP) e 86,7\% (M+GA) da massa seca total. Esses valores demonstram maior capacidade produtiva do milheto em relação a outras culturas em semeaduras realizadas a partir do mês de março.

TABELA 9 - Produção de matéria seca em vários estádios de desenvolvimento avaliados em Dias Após a Semeadura (DAS), em três cultivares de milheto

\begin{tabular}{|c|c|c|c|c|}
\hline \multirow{2}{*}{$\begin{array}{l}\text { Estádio de } \\
\text { desenvolvimento }\end{array}$} & \multirow{2}{*}{ DAS } & \multicolumn{3}{|c|}{ Matéria Seca (t ha $\left.{ }^{-1}\right)$} \\
\hline & & ADR 500 & ADR 300 & BN2 \\
\hline Pré-emborrachamento & 36 & $3,52 \mathrm{Ad}$ & $3,47 \mathrm{Ad}$ & $2,55 \mathrm{Ad}$ \\
\hline Pré-florescimento & 45 & $6,31 \mathrm{Ac}$ & $5,01 \mathrm{Abc}$ & $4,21 \mathrm{Bc}$ \\
\hline Início florescimento & 52 & $9,35 \mathrm{Ab}$ & $8,75 \mathrm{Ab}$ & $5,81 \mathrm{Bb}$ \\
\hline Pleno florescimento & 59 & $19,29 \mathrm{Aa}$ & $19,69 \mathrm{Aa}$ & $8,12 \mathrm{Ba}$ \\
\hline \multicolumn{5}{|c|}{$\begin{array}{l}\text { Médias seguidas de letras iguais, maiúsculas na linha e minúsculas na coluna, não diferem pelo } \\
\text { teste Duncan a } 5 \% \text {. } \\
\text { FONTE: PIRES et al., (2007) }\end{array}$} \\
\hline \multicolumn{5}{|c|}{$\begin{array}{l}\text { AMARAL (2003), trabalhando com várias idades de corte também } \\
\text { encontrou quantidade crescente de massa seca, verificou ainda que a massa } \\
\text { seca atingiu um ponto máximo até o segundo corte com } 90 \text { dias e depois } \\
\text { decresceu nos cortes seguintes. Os teores de proteína bruta decresceram à } \\
\text { medida que a idade de corte avançou. Houve aumento crescente nos valores } \\
\text { do FDN e FDA com o avanço da idade de corte, devido ao aumento da parede } \\
\text { celular reduzindo a qualidade da forrageira ao longo do período e diminuição } \\
\text { do seu valor nutritivo (Tabela } 10 \text { ). Resultado semelhante também foi } \\
\text { encontrado por NICOLAU SOBRINHO (2007) trabalhando com vários tipos de } \\
\text { adubação de semeadura para a cultura do milheto e por MULLER et al., (2005) } \\
\text { quando trabalharam com cultivo hidropônico de milheto. }\end{array}$} \\
\hline
\end{tabular}


BUSO, W.H.D. et al. Uso do milheto na alimentação animal. PUBVET, Londrina, V. 5, N. 22, Ed. 169, Art. 1136, 2011.

TABELA 10 - Composição bromatológica de cultivares de milheto submetidas a quatro idades de corte

\begin{tabular}{ccccc}
\hline \multirow{2}{*}{ Cultivares } & \multicolumn{4}{c}{ Idades (dias) } \\
\cline { 2 - 5 } & 70 & \multicolumn{4}{c}{160} \\
\hline \multicolumn{5}{c}{ Matéria seca (\%) } \\
\hline BRS 1501 & $20,16 \mathrm{a}$ & $33,04 \mathrm{~b}$ & $77,95 \mathrm{a}$ & $83,05 \mathrm{a}$ \\
BN1 & $22,45 \mathrm{a}$ & $36,92 \mathrm{a}$ & $73,25 \mathrm{a}$ & $76,34 \mathrm{a}$ \\
Comum & $24,68 \mathrm{a}$ & $37,22 \mathrm{a}$ & $70,53 \mathrm{a}$ & $75,02 \mathrm{a}$ \\
\hline BRS 1501 & $10,09 \mathrm{a}$ & Proteína bruta (\% MS) \\
BN1 & $9,93 \mathrm{a}$ & $8,14 \mathrm{a}$ & $6,20 \mathrm{a}$ & $6,60 \mathrm{a}$ \\
Comum & $10,51 \mathrm{a}$ & $9,86 \mathrm{a}$ & $7,00 \mathrm{a}$ & $6,66 \mathrm{a}$ \\
\hline
\end{tabular}

Fibra em detergente neutro (\% MS)

\begin{tabular}{ccccc}
\hline BRS 1501 & $66,73 \mathrm{a}$ & $70,91 \mathrm{a}$ & $79,14 \mathrm{a}$ & $85,98 \mathrm{a}$ \\
BN1 & $63,67 \mathrm{a}$ & $66,98 \mathrm{a}$ & $84,79 \mathrm{a}$ & $87,22 \mathrm{a}$ \\
Comum & $64,56 \mathrm{a}$ & $67,52 \mathrm{a}$ & $80,48 \mathrm{a}$ & $83,42 \mathrm{a}$ \\
\hline \multicolumn{5}{c}{ Fibra em detergente ácido (\% MS) } \\
\hline BRS 1501 & $38,12 \mathrm{a}$ & $36,89 \mathrm{a}$ & $45,43 \mathrm{ab}$ & $49,94 \mathrm{a}$ \\
BN1 & $34,37 \mathrm{a}$ & $34,43 \mathrm{a}$ & $48,69 \mathrm{a}$ & $50,16 \mathrm{a}$ \\
Comum & $35,36 \mathrm{a}$ & $36,16 \mathrm{a}$ & $44,47 \mathrm{~b}$ & $47,82 \mathrm{a}$
\end{tabular}

Médias seguidas de mesma letra minúsculas nas colunas não diferem estatisticamente pelo teste de Tukey a $5 \%$.

FONTE: AMARAL (2003)

Trabalhando com três idades de cortes diferentes KOLLET et al., (2006) observaram que à medida, que aumenta a idade de corte aumenta a produção de massa seca. O teor de proteína bruta apresentou decréscimo, os teores de FDN e FDA aumentaram devido a redução de lâminas foliares e aumento das hastes, elevando os componentes fibrosos (Tabela 11). 
BUSO, W.H.D. et al. Uso do milheto na alimentação animal. PUBVET, Londrina, V. 5, N. 22, Ed. 169, Art. 1136, 2011.

TABELA 11 - Teores de massa seca, proteína bruta, fibra em detergente neutro e fibra em detergente ácido de três variedades de milheto (Pennisetum glaucum(L.) R Br.) submetidos a três idades de corte

\begin{tabular}{|c|c|c|c|}
\hline \multirow{2}{*}{ Cultivares } & \multicolumn{3}{|c|}{ Idade dos cortes (dias) } \\
\hline & 35 & 42 & 49 \\
\hline & \multicolumn{3}{|c|}{ Massa seca $\left(\mathrm{kg} \mathrm{ha}^{-1}\right)$} \\
\hline Africano & 2.937 & 3.918 & 6.224 \\
\hline Americano & 2.747 & 3.013 & 6.854 \\
\hline \multirow[t]{2}{*}{$\mathrm{BN}-2$} & 2.038 & 2.669 & 5.032 \\
\hline & \multicolumn{3}{|c|}{ Proteína Bruta (\%) } \\
\hline Africano & 17,93 & 14,51 & 13,66 \\
\hline Americano & 20,64 & 15,59 & 13,90 \\
\hline \multirow[t]{2}{*}{$\mathrm{BN}-2$} & 19,41 & 16,17 & 13,32 \\
\hline & \multicolumn{3}{|c|}{ Fibra em detergente neutro (\%) } \\
\hline Africano & 54,30 & 58,19 & 69,17 \\
\hline Americano & 53,12 & 54,74 & 61,02 \\
\hline \multirow[t]{2}{*}{$\mathrm{BN}-2$} & 51,68 & 54,43 & 61,69 \\
\hline & \multicolumn{3}{|c|}{ Fibra em detergente ácido (\%) } \\
\hline Africano & 31,43 & 35,36 & 36,97 \\
\hline Americano & 28,26 & 29,11 & 32,77 \\
\hline $\mathrm{BN}-2$ & 27,52 & 30,98 & 34,43 \\
\hline
\end{tabular}

FORNTE: KOLLET et al., (2006)

A adubação nitrogenada promoveu incrementos lineares de massa seca e proteína bruta, obtidos em cinco cortes, estes incrementos variaram em função das doses de N, conforme pode ser observado nas Figuras 5 e 6 (SILVA et al., 1996). 
BUSO, W.H.D. et al. Uso do milheto na alimentação animal. PUBVET, Londrina, V. 5, N. 22, Ed. 169, Art. 1136, 2011.

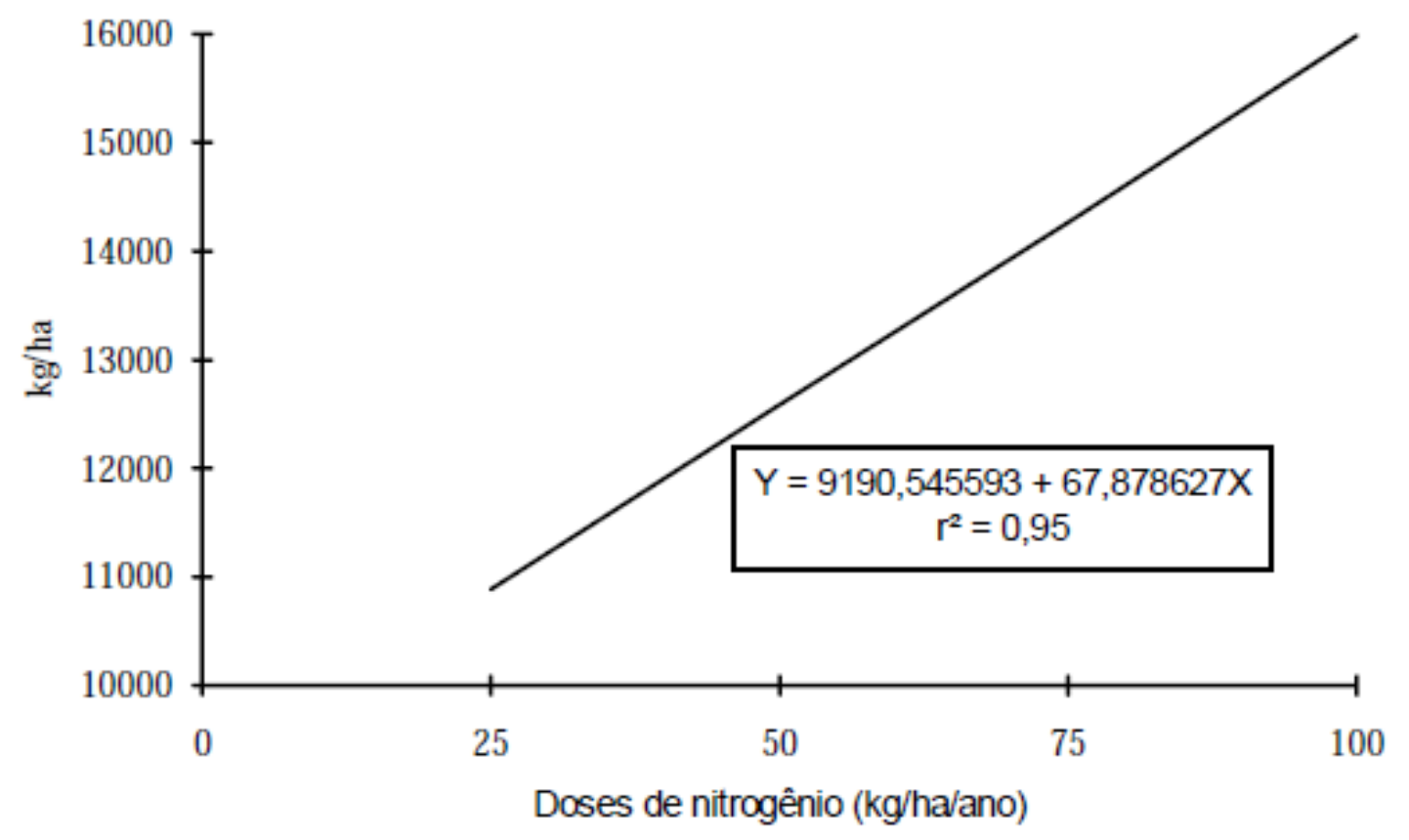

FIGURA 5 - Relação entre a produção total de matéria seca (5 cortes) e as doses crescentes de nitrogênio (SILVA et al., 1996)

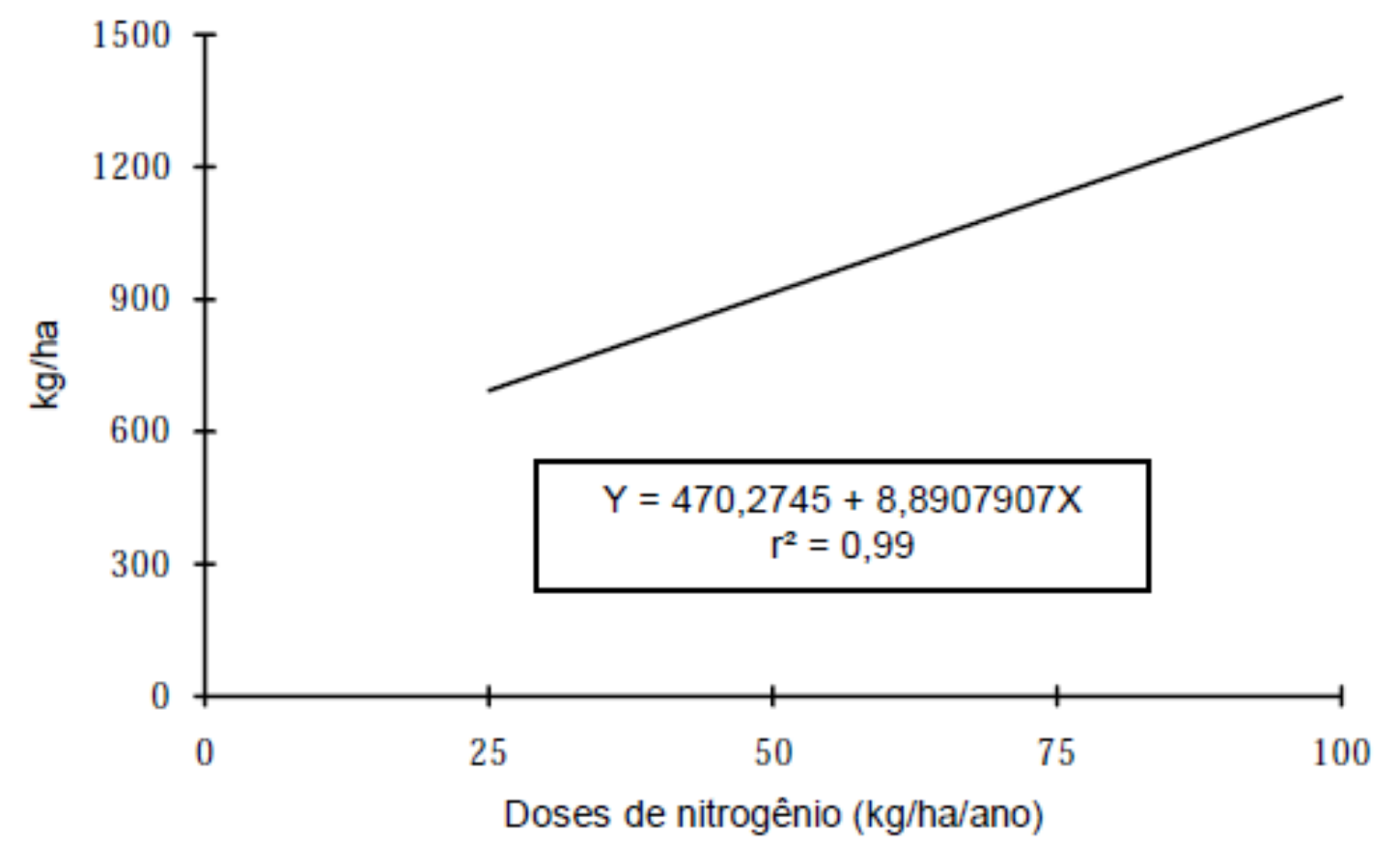

FIGURA 6 - Relação entre a produção total de proteína ( 5 cortes) e as doses de nitrogênio aplicadas (SILVA et al., 1996) 
BUSO, W.H.D. et al. Uso do milheto na alimentação animal. PUBVET, Londrina, V. 5, N. 22, Ed. 169, Art. 1136, 2011.

\section{CONSIDERAÇÕES FINAIS}

- Comparativamente à maioria das forrageiras tropicais, o milheto é uma alternativa para melhorar a qualidade alimentar dos animais. Apresenta alta produtividade e precocidade, durante períodos de escassez das forrageiras perenes.

- As pastagens de milheto podem funcionar como suplemento protéico e energético, principalmente durante o período seco. A intercalação desta forrageira com as pastagens perenes resulta numa melhoria considerável na dieta dos animais.

- O cultivo do milheto após as colheitas de verão (soja e milho) é de fundamental importância para implementação e o sucesso da integração agricultura $\mathrm{x}$ pecuária.

\section{REFERÊNCIAS}

AMARAL, P.N.C. Silagem e rolão de milheto em diferentes idades de corte. 2003.78 f. Dissertação (Mestrado em Zootecnia). Universidade Federal de Lavras, Lavras.

BASTOS, A.O.; LANDELL FILHO, L.C.; PASSIPIERI, M.; BASTOS, J.F.P. Diferentes níveis de grãos de milheto (Pennisetum glaucum (L.) R. Brown) na alimentação de suínos. Revista Brasileira de Zootecnia, Viçosa, v.31, n.4, p.1753-1760, 2002.

BASTOS, A.O.; MOREIRA, I,. FURLAN, A.C.; FRAGA, A.L.; OLIVEIRA, R.P.; OLIVEIRA, E. Composição química, digestibilidade dos nutrientes e da energia de difetentes milhetos (Pennisetum glaucum (L.) R. Brown) em suínos. Revista Brasileira de Zootecnia, Viçosa, v.34, n.2, p.520-528, 2005.

BASTOS, A.O.; MOREIRA, I,. FURLAN, A.C.; OLIVEIRA, G.C.; FRAGA, A.L.; SARTORI, I.M. Efeito da inclusão de níveis crescentes de milheto (Pennisetum glaucum (L.) R. Brown) grão na alimentação de suínos em crescimento e terminação. Revista Brasileira de Zootecnia, Viçosa, v.35, n.1, p.98-103, 2006.

BOGDAN, A.V. Tropical pasture and fodder plants (grasses and legumes). Lodon: Logman, 1977, 241p. (Tropical Agriculture Series).

BRUM, M.S.; QUADROS, F.L.F.; MARTINS, J.D.; ROSSI, F.E.; DANIEL, E.; MAIXNER, A.R.; BANDINELLI, D.G. Sistemas de alimentação para a recria de ovinos a pasto:avaliação do desempenho animal e características da forragem. Ciência Rural, Santa Maria, v.38, n.1, p.191-198, 2008. 
BRUKEN, J.N. A systematic study of Pennisetum Sect. Pennisetum (Graminea). American Journal of Botany, New York, v. 64, n. 2, p.161-176, 1977.

CAFÉ, M.B.; STRINGHINI, J.H.; MOGYCA, N.S.; FRANÇA, A.F.S.; ROCHA, F.R.T. Milheto-grão (Pennisetum glaucum (L.) R.Br.) como substituto do milho em rações para poedeiras comerciais. Arq. Bras. med. Vet. Zootec., Belo Horizonte, v.51, n.2, 1999. Disponível em: http://www.scielo.br/scielo.php?script $=$ sci arttext\&pid $=$ S010209351999000200009\&lng=en\&nrm=iso\&tlng=pt. Acesso em: 30 de mai de 2010.

CAMARGO, D.G.; ROCHA, M.G.; KOZLOSKI, G.V.; ELEJALDE, D.G.; BREMM, C.; POTTER, L.; ROSA, A.T.N.; OLIVEIRA NETO, R.A. Consumo de forragem por cordeiras suplementadas em pastagem de milheto. Ciência Rural, Santa Maria, v.39, n.2, p.509-514, 2009.

CASTRO, C.R.C. Relações planta-animal em pastagens de milheto (Penissetum americanum (I.) Leeke) manejada em diferentes alturas com bovinos. 2002. $185 f$. Dissertação (Mestrado em Zootecnia) Universidade Federal do Rio Grande do Sul.

CAZETTA, D.A.; FORNASIERI FILHO, D.; GIROTTO, F. Composição, produção de matéria seca e cobertura do solo em cultivo exclusivo e consorciado de milheto e crotalária. Acta Sci. Agron, Maringá, v.27, n.4, p.575-580, 2005.

COIMBRA, R.A.; NAKAGAWA, J. Época de semeadura e regimes de corte na produção de milheto forrageiro. Revista Brasileira de Milho e Sorgo, Sete Lagoas, v.5, n,1, p.89-100, 2006.

COSTA, V.G. Comportamento de pastejo e ingestão de forragem por novilhas de corte em pastagens de milheto e papua. 2009. 69 f. Dissertação (Mestrado em zootecnia). Universidade Federal de Santa Maria, Santa Maria.

FRANÇA, A.F.S.; ORSINE, F.F.; DIAS, M.J.; STRINGHINI, J.H.; PÁDUA, J.T.; PÁDUA, D.M.C.; MUNDIN, S.P. Utilização do milheto como substituto do milho em rações para cabras leiteiras. Anais Esc. Agron. Vet., Goiânia, v.26, n.2, p.89-95, 1996.

FRIBOURG, H. A. Summer annual grasses. In: HEAT, M.E.; BARNES, R.F.; METCALFE, D. S. Forages: the science of grassland agriculture. Iowa State University. Ames, Iowa. 4. ed. p.278286, 1985.

GONÇALVES, E.N.; QUADROS, F.L.F. Morfogênese de milheto (Pennisetum americanum (L.) Leeke) em pastejo com terneiras, recebendo ou não suplementação. Ciência Rural, Santa Maria, v.33, n.6, p.1123-1128, 2003.

GUIMARÃES JÚNIOR, R. Potencial forrageiro, perfil de fermentação e qualidade das silagens de três genótipos de milheto [Pennisetum glaucum (I). R. Br.]. 2003. $44 \mathrm{f}$. Dissertação (Mestrado em Ciência Animal). Escola de Veterinária, Universidade Federal de Minas Gerais, Belo Horizonte.

GUIMARÃES JÚNIOR, R.; GONÇALVES, L.C.; RODRIGUES, J.A.S.; JAYME, D.G.; PIRES, D.A.A.; BORGES, A.L.C.C.; RODRIGUEZ, N.M.; SALIBA, E.O.S.; BORGES, I. Matéria seca, proteína bruta, nitrogênio amoniacal e pH das silagens de três genótipos de milheto [Pennisetum glaucum $(L)$. $R$. $\mathrm{Br}$.] em diferentes períodos de fermentação. Revista Brasileira de Milho e Sorgo, Sete Lagoas, v.4, n,2, p.251-258, 2005.

GUIMARÃES JÚNIOR, R. Avaliação nutricional de silagem de milheto [Pennisetum glaucum (L). R. Br.]. 2006. 90 f. Tese (Doutor em Ciência Animal). Escola de Veterinária, Universidade Federal de Minas Gerais, Belo Horizonte. 
JAMIESON, W. S.; HODGSON, J. The effect of daly herbage allowance and sward characteristics upon the ingestive behavior of calves under strip-grazing management. Grass and Forage Science, Oxford, v.34, p.261-271, 1979.

JOCHIMS, F.; PIRES, C.C.; GRIEBLER, L.; BOLZAN, A.M.S.; DIAS F.D.; GALVANI, D.B. Comportamento ingestivo e consumo de forragem por cordeiras em pastagem de milheto recebendo ou não suplemento. Revista Brasileira de Zootecnia, Viçosa, v.39, n.3, p.572$581,2010$.

LEANDRO, N.S.M.;, STRINGHINI, J.H.; CAFÉ, M.B.; FRANÇA, A.F.S.; FREITAS, S.A. Milheto (Pennisetum glaucum (L.) R.Br.) como substituto do milho em rações para codornas-japonesas em postura (Coturnix coturnix japônica). Arq. Bras. med. Vet. Zootec., Belo Horizonte, v.51, n.2, 1999. Disponível em: http://www.scielo.br/scielo.php?script=sci arttext\&pid=S0102-

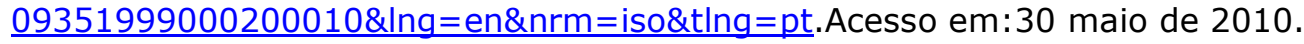

KICHEL, A.N.; MIRANDA, C.H.B. Uso do milheto como planta forrageira. 2000. Disponível em: http://www.cnpgc.embrapa.br/publicacoes/divulga/GCD46.html. Acesso em: 02 de jun de 2010.

KOLLET, J.L.; DIOGO, J.M.S.; LEITE, G.G. Rendimento forrageiro e composição bromatológica de variedades de milheto (Pennisetum glaucum(L.)R. BR.). Revista Brasileira de Zootecnia, Viçosa, v.35, n.4, p.1308-1315, 2006.

MARTINS, C.E.N.; QUADROS, F.L.F.; BANDINELLI, D.G.; SIMÕES, L.F.C.; KLOSS, M.G.; ROCHA, M.G. Variáveis morfogênicas de milheto (Pennisetum americanum) mantido em duas alturas de pastejo. Revista Ciência Rural, Santa Maria, v.35, n.1, p.174-180, 2005.

MONTANGNER, D. P. Estrutura da pastagem, comportamento ingestivo e consumo voluntário de forragem de novilhas de corte em pastagem de milheto (pennisetum americanum (L.) Leeke). 2004. 133 f. Dissertação (Mestrado em Zootecnia). Escola de Veterinária, Universidade Federal de Santa Maria, Santa Maria.

MONTAGNER, D.B.; ROCHA, M.G.; SANTOS, D.T.; GENRO, T.C.M.; QUADROS, F.L.F.; ROMAN, J.; POTTER, L.; BREMM, C. Manejo da pastagem de milheto para recria novilhas de corte. Revista Ciência Rural, Santa Maria, v.38, n.8, p. 2293-2299, 2008.

MOOJEN, E.L.; RESTLE, J.; LUPATINI G.C.; MORAES, A.G. Produção animal em pastagem de milheto sob diferentes níveis de nitrogênio. Pesquisa Agropecuária Brasileira, Brasília, v.34, n.11, p.2145-2149, 1999.

MOREIRA, L.B.; MALHEIROS, M.G.; CRUZ, B.B.G.; ALVES, R.E.A.; OLIVEIRA, R.S. Efeitos da população de plantas sobre as características morfológicas e agronômicas de milheto pérola (Pennisetum glaucum (L.) R. Brown) cv. ENA 1. Agronomia, Seropédica, v.37, n.1, p.05-09, 2003.

MULLER, L.; SANTOS, O.S.; MANFRON, P.A.; HAUT, V.; FAGAN, E.B.; MEDEIROS, S.L.P.; DOURADO NETO, D. Produção e qualidade bromatológica de gramíneas em sistema hidropônico. Rev. Fac. Zootec. Vet. Agro., Uruguaiana, v.12, n.1, p.152-161, 2005.

NICOLAU SOBRINHO, W. Adubação orgânica e mineral na composição química e produção do milheto (Pennisetum claucum) no semi-árido. 2007. 63 f. Dissertação (Mestrado em Zootecnia). Universidade Federal de Campina Grande, Patos. 
PEDROSO, C.E.S.; MONKS, P.L.; FERREIRA, O.G.L.; TAVARES, O.M.; LIMAS, L.S. Características estruturais de milheto sob pastejo rotativo com diferentes períodos de descanso. Revista Brasileira de Zootecnia, Viçosa, v.38, n.5, p. 801-808, 2009.

PILAU, A.; LOBATO, J.F.P. Manejo de novilhas prenhes aos 13/15 meses de idade em sistema a pasto. Revista Brasileira de Zootecnia, Viçosa, v.37, n.7, p. 1271-1279, 2008.

PIRES, F.B.; ASSIS, R.L.; SILVA, G.P.; BRAZ, A.J.B.P; SANTOS, S.C.; VIEIRA NETO, S.A.; SOUSA, J.P.G. Desempenho agronômico de variedades de milheto em razão da fenologia em pré-safra. Biosci. J., Uberlândia, v.23, n.3, p. 41-49, 2007.

RIBEIRO, C.V.M.; PIRES, A.V.; SIMAS, J.M.C.; SANTOS, F.A.P.; SUSIM, I.; OLIVEIRA JUNIOR, R.C. Substituição de grão de milho pelo milheto (Pennisetum americanum) na dieta de vacas holandesas em lactação. Revista Brasileira de Zootecnia, Viçosa, v.33, n.5, p.1351-1259, 2004.

ROMAN, J.; ROCHA, M.G.; GENRO, T.C.; SANTOS, D.T.; FREITAS, F.K.; MONTAGNER, D.B. Características produtivas e estruturais do milheto e sua relação com o ganho de peso de bezerras sob suplementação alimentar. Revista Brasileira de Zootecnia, Viçosa, v.37, n.2, p.205-211, 2008.

SANTOS, H.P.; FONTANELI, R.S.; BAIER, A.C.; TOMM, G.O. Principais forrageiras para integração lavoura-pecuária, sob plantio direto, nas regiões Planalto e Missões do Rio Grande do Sul. Passo Fundo, EMBRAPA TRIGO, 2002. 142p.

SCARAVELLI, L.F.B.; PEREIRA, L.E.T.P.; OLIVO, C.J.; AGNOLIN, C.A. Produção e qualidade de pastagens de Coastcross-1 e milheto utilizadas com vacas leiteiras. Ciência Rural, Santa Maria, v. 37, n.3, p.841-846, 2007.

SCHEFFER-BASSO, S. M.; AGRANIONIK, H.; FONTANELI, R. S. Acúmulo de biomassa e composição bromatológica de milheto das cultivares comum e africano. Rev. bras. Agrociência, Pelotas, v.10, n.4, p.483-486, 2004.

SCHWARTZ, F.; ROCHA, M.G.; VÉRAS, M.; FARINATTI, L.H.; PIRES, C.C.; CELLA JUNIOR, A.A. Manejo de milheto (Pennisetum americanum LEEKE) sob pastejo de ovinos. Rev. Bras. Agrociência, Pelotas, v.9, n.2, p.151-155, 2003.

SILVA, R.M.; SIEWERDT, L.; SILVEIRA JÚNIOR, P.; SIEWERDT, F. Nível e fracionamento da aplicação do nitrogênio na produção de forragens em campo natural de planossolo. Rev. Bras. Agrociência, Pelotas, v.2, n.1, p.39-44, 1996.

SILVA, G.F.; ERASMO, E.A.L.; SARMENTO, R.A.; SANTOS, A.R.; AGUIAR, R.W.S. Potencial de produção de biomassa e matéria seca de milheto (Pennisetum americanum Schum.), em diferentes épocas no sul do tocatins. Biosci. J., Uberlândia, v.19, n.3, p.31-34, 2003.

SOUSA, D.M.G.; LOBATO, E. Calagem e adubação para culturas anuais e semiperenes. In: SOUZA, D.M.G.; LOBATO, E. Cerrado correção do solo e adubação. 2.ed. Brasília. 2004. cap. 12, p.305-306.

TEIXEIRA, C.M.; CARVALHO, G.J.; ANDRADE, J.B.; FURTINI NETO, A.E. Fitomassa, teor e acúmulo de micronutrientes do milheto, feijão-de-porco e gruandu-anão, em cultivo solteiro e consorciado. Acta Sci. Agron., Maringá, v.30, n.4, p.533-538, 2008. 